\title{
The Risk of Electronic Audit and Its Impact on The Quality Audit
}

\author{
Zainab Jabbar Yousif Khawla Shehab Najem \\ Southern Technical University, Basra Technical Institute \\ zaniabyosif@yahoo.com Kalmossawi@Yahoo.Com
}

Keywords: Audit risk, Audit techniques , electronic audit, audit quality

\begin{abstract}
The auditing profession faces a challenge referred to as information technology ,Information technology has set the profession of auditing in constant challenge because it has made the world an open - limited system through communication technology .

The importance of this research stems from the need to identify the nature of the risks of electronic auditing after turned from manual checking to electronic auditing due to developments in technologies in all sectors. The risk of electronic auditing the risk of information technology infrastructure and the risks of applications and other related to communication processes, several conclusions have been reached, implementation of programs with goods specifications in the electronic auditing process will lead to safety of work and reduce the risk of electronic auditing. The research highlights these risks and their impact on the quality of auditing .

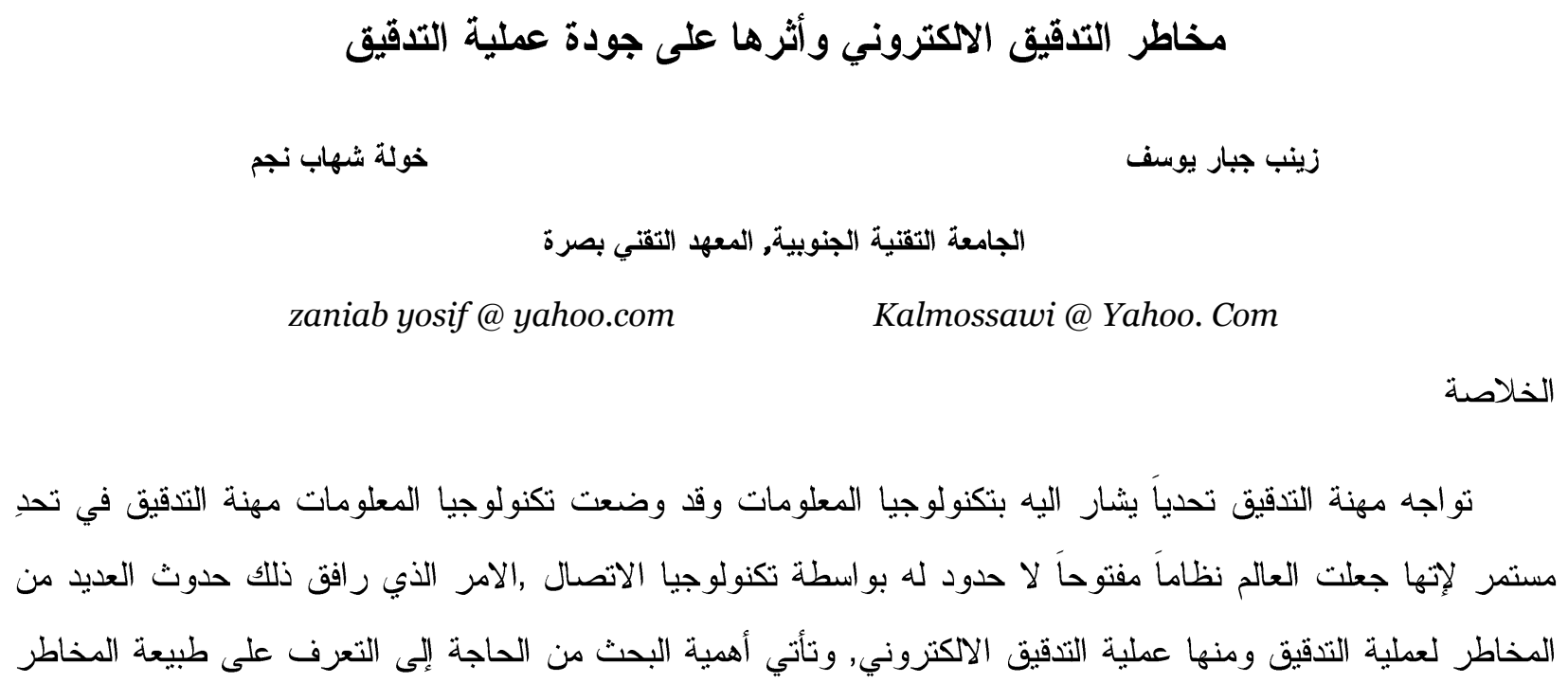


الناتجة من تكنولوجيا الاتصال واثرها على جودة التذقيق بعد أن تحولت عملية التدقيق من التدقيق الــــدوي إلى التذقــــق الاكتروني بفعل التطورات والتقنيـات التي شهدتها جميع القطاعات ,وتتمثل تلك المخاطر بالبنية التحتية وتطبيقات تكنولوجيا المعلومات فضلا عن عمليات الاتصال, وقد تم التوصل الى العديد من الاستتناجات منها الاهتمام بتطبيق البرامج ذات المواصفات الجيدة في عملية التدقيق الاككتروني من شأنه أن يؤدي إلى الاطمئنان على سلامة العمل و تقليل مخاطر التدقيق الاككتروني , وقد جاء البحث ليسلط الضوء على تلك المخاطر و أثرها على جودة التدقيق.

الكلمات المفتاحية: مخاطر التدقيق, تقنيات التدقيق, التذقيق الاككتروني, جودة التذقيق.

المقدمة

شهدت القطاعات الاقتصادية تغيرات واسعة في بيئتها التكنولوجية , حيث نم استخدام الحاسبات الالكترونية في معالجة عملياتها الاقتصاديةروهذا الامر يتطلب من مهنة التدقيق مسايرة تلك التطـورات وذلكك من خلال جعل تدقيق العمليات يمر بصورة سريعة. وبسبب ظهور أنظمة البرامج المحاسبية المبنية على تكنولوجيا المعلومات وتطورها لدى العديد من المنشآت فأن الضرورة باتت ملحة من استخدام تكنولوجيا المعلومات في عملية التدقيق.

لذلك اصبح من الضروري على مدقق الحسابات مواكبة هذه التطور ات وذلك بأن يقوم بتطوير نفسه و اسلوب التدقيق الذي يستخدمه بما يتلاءم مع تلك التطورات, وفي نفس الوفت يقابل تلك النطورات في تكنولوجيا المعلومات العديد من المخاطر منها مخاطر التدقيق الالكتروني سواء كانت نلك المخاطر ناجمة عن البنية التحتية لتكنولوجيا المعلومات او عن التطبيقات او عن عمليات الاتصال. وقد جاء البحث ليسط الضوء على تلك المخاطر واثزها على جودة عملية التدقيق. وعليه فقد تضمن البحث جانبين نظري وعملي الجانب النظري خصص للتعرف على اساليب واجراءات التدقيق الالكتروني بالاضافة الى التعرف غلى مخاطر التدقيق بشكل عام سواء كان التذقيق يدوياً أم الياً فضلا عن التعرف على

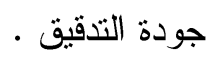

اما الجانب الثاني فهو خاص بالجانب العملي حيث تضمن استمارة الاستبيان واجراء العديد من الاختبارات الخاصة بها لغرض التأكد من صحة الفرضيات الخاصة بالبحث, وقد توصلت الدراسة إلى العديد من الاستنتاجات و التوصيات الخاصة بالبحث اعتماداً على نتائج التحليل. 


\section{منهجية البحث}

اولا: مشكلة البحث

تو اجه مهنة التدقيق تحديًا يشار اليه بتكنولوجيا المعلومات , وقد وضعت تكنولوجيا المعلومات مهنة التدقيق في تحد مستمر لأنها جعلت العالم نظاما مفتوحا لا حدود له من خلال تكنولوجيا الاتصال .

وعلى الرغم من المزايا العديدة التي يحققها الحاسب الاككتروني الا انه يؤدي حدوث الكثير من المشاكل فضدا عن المخاطر الناشئة والناتجة عن عملية التدقيق مما يتطلب ضرورة الاهتمام بكفاءة وفعالية عمليات الأتمتة بالأضافة الى احداث تغيرات في الهيكل التنظيمي للمنشأة لتوفير جو ملائم لأستخدام الحاسب في عملية التذقيق , وبناءا على ماسبق فأن مشكلة البحث تتمثل بالسؤال الرئيس التالي : مامدى تأثير مخاطر التدقيق الالكتروني على جودة التدقيق ؟ ويتفرع من السؤال الرئيس الأسئلة الفرعية التالية :

ا- مامدى تأثنير مخاطر البنية التحتية لتكنولوجيا المعلومات على جودة التدقيق ؟.

r- ماددى تأثير تطبيقات تكنولوجيا المعلومات على جودة التدقيق ؟.

ب- مامدى تأثثر عمليات الاتصال على جودة التدقيق ؟.

ثاتيا :أهمبة البحث

تتبع اهمية البحث من الحاجة إلى التعرف على طبيعة المخاطر الخاصة بالتدقيق الالكتروني من ناحية (البنية التحنية تطبيقات تكنولوجيا المعلومات فضدا عن عمليات الاتصال) ومدى تأثيرها في أداء مهمة التدقيق وتزداد أهمية البحث في تحديد كيفية مواجهة التحدي المستمر لتكنولوجيا المعلومات وبالثكل الذي يؤدي الى الارنقاء بجودة عملية التدقيق واساليبها لتتلاعم مع التطور التكنولوجي المستمر في المعالجة الالية للبيات خصوصا بعد أن اصبحت التقة بجودة عملية التنقيق مطلب اساسي عند اعداد الكشوفات و القو ائم المالية و المعول عليه في ذلك .

ثالثا:هدف البحث

يهدف البحث إلى بيان تاثير مخاطر التدقيق الاككتروني على جودة عملية التدقيق للبيانات والتعرف على دور معايير التذقيق الدولية في علاج فجوة الاداء في بيئة تكنولوجيا المعلومات بشكل رئيسي ويتفرع من هذا الهدف الرئيس

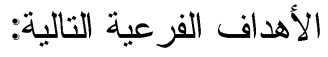

1- در اسة مدى تأثير مخاطر البنية التحتية لتكنولوجيا المعلومات على جودة التدقيق. 
Journal of University of Babylon for Pure and Applied Sciences,Vol.(26), No.(7): 2018

$$
\begin{aligned}
& \text { r- التعرف على مدى تأثير معلومات عمليات الاتصلال على جودة التذقيق على جودة التدقيق. } \\
& \text { ب- الوقوف على مدى تأثير تطبيقات تكنولوجيا المعلومات على جودة التذقيق . } \\
& \text { رابعا : فرضية البحث:يقوم البحث على فرضيتين رئيسيتين هما: }
\end{aligned}
$$

الفرضية الرئيسية الاولى: لا يوجد تأثير ذو دلالة إحصائية لمخاطر التدقيق الالكتروني على جودة عملية التذقيق ,

$$
\text { وتتقرع من هذه الفرضية الفرضيات الفرعية التالية : }
$$

ا- الفرضية الفرعية الاولى: لا يوجد تأثير ذو دلالة إحصائية لمخاطر البنية التحتية لتكنولوجيا المعلومات على جودة

$$
\text { عملية التدقيق من وجهة نظر مدققي الحسابات. }
$$

r- r-الفرضية الفرعية الثانية: لا يوجد تأثير ذو دلالة احصائية لتطبيقات تكنولوجيا المعلومات على جودة التذقيق

$$
\text { من وجهة نظر مدققي الحسابات. }
$$

بـ- الفرضية الفرعية الثالثة: لا يوجد تأثير ذو دلالة احصائية لعمليات الاتصال على جودة التدقيق من وجهـة نظر

$$
\text { مدقي الحسابات . }
$$

الفرضية الرئيسية الثانية : توجد فروقات ذات دلالة احصائية في منوسطات استجابات المبحوثين حول أثرمخاطر بيئة التدقيق الاككتروني على جودة التدقيق خاصة بالمتغيرات الثخصية ( بالمؤهل العلمي , العمر بالسنوات وعدد سنوات الخبرة), ويتفرع من هذه الفرضية الفرضيات الفرعية التالية :

ا- الفرضية الفرعية الاولى: توجد فروقات ذات دلالة احصائية في متوسطات استجابات المبحوثين حول أثر مخاطر التذقيق الاككتروني على جودة عملية التذقيق تعزى بالمؤهل العلمي. r- الفرضية الفرعية الثانية: نوجد فروقات ذات دلالة احصائية في منوسطات استجابات المبحوثين حول اثر مخاطر التذقيق الاككتروني على جودة عملية التذقيق تعزى للعمر بالسنوات.

س- الفرضية الفرعية الثالثة: توجد فروقات ذات دلالة احصائية في متوسطات استجابات المبحوثين حول اثر مخاطر التنقيق الاككتروني على جودة عملية التدقيق تعزى لعدد سنوات الخبرة .

خامسا : ألاساليب المستخدمة تم استخدام العديد من الاختبارات والاساليب الاحصائية لتحليل استمارة الاستبيان والتحقق من صحة الفرضيات الخاصة بالبحث . 
Journal of University of Babylon for Pure and Applied Sciences,Vol.(26), No.(7): 2018

$$
\text { أولَا : الجانب النظري }
$$

الفصل الأول: أساليب التدقيق الاككتروني وإجراءاته ومخاطره

المبحث الأول:أساليب التدقيق الاكتروني وإجراعته

اولا: اساليب التدقيق الآكتروني ومراحل الاجراء .

تتير اساليب التدقيق الاككتروني الى استخدام المدقق مجموعة من البرامج أثناء قيامه بتنفيذ المهام الموكل بها

[1]: وهناك نوعين رئيسيين من البرامج المستخدمة في تلك الحالة هما 1- 1 - مبرامج التدقيق العامة

و هي مجموعة من البرامج التي تقوم بتنفيذ عمليات التنقيق في ظل نظم المعلومات المحاسبية الاككترونية , وتستخدم هذه البرامج في أداء الاختبار ات الجوهرية للبيانات محل التذقيق . r- بر بر امج التدقيق الخاصة

و هي مجموعة من البرامج يتم تصميمها من قبل المدقق لتتلاءم مع متطلبات عمل المنشأة و هذا النوع من البرامج يتطلب مهارة ودراية بعمل الحاسب من قبل المدقق لغرض نجاح عملية التذقيق , وهناك عدة مراحل يتم القيام بها [2]: لغرض اجراء عملية التذقيق الآكتروني وهي ا- مرحلة قبول التكليف r- مرحلة تخطيط عملية التذقيق ب- مرحلة تتفيذ عملية التذقيق ع- مرحلة التقرير • ا- مرحلة قبول التكليف : يو اجه المدقق مخاطر قبول التكليف , وهو الخطر الناتج من احتمال تعرض المراجع لمساعلة قانونية ومهنية ينتج عنها غالباً خسائر مادية نتيجة لقبوله لأعمال التكليف ووجود احتمال الأ يلتزم بمعايير المراجعة في اداء اعمال التكليف ـ ويجب على المدقق الحصول على معلومات تتعلق بالمنشأة بمدى قوة مركز ها المالي ومعلومات عن النظام المحاسبي الاككتروني ومدى ارتفاع المخاطر في طبيعة نشاط المنشأة.

r- مرحلة تخطيط عملية التدقيق : وهي مرحلة زيادة التعمق في المعلومات والتوسع في بناء قاعدة البيانات للبدء بعملية التخطيط للمر اجعة ليتمكن من تقدير كل من الخطر الحتمي وخطر الرقابة , ويستطيع المدقق من طريق الاجراءات التحليلية من تعزيز فهمه لنشاط الثركة وذلك بأستخدام اساليب مراجعة نظم نظم المعلومات المحاسبية الاكترونية .

ب- مرحلة تتفيذ عملية التدقيق : بعد اعداد الخطة العامة وبر امج التدقيق تأتي مرحلة تتفيذ الخطة وتهدف هذه المرحلة إلى جمع ادلة اثبات كافية وملائمة ويقوم المدقق في هذه المرحلة تنفيذ نوعين من الاختبار ات في ظل الأتمتة هما : 
أ- اختبارات مدى الالتزام : وهي اختبارات تهدف للحصول على ادلة اثبات ملائمة عن طريق اختبار مدى كفاءة وفعالية الرقابة الداخلية المتعلقة بمزاعم الادارة بشكل غير مباشر (الرقابة العامة) ونظام الرقابة الداخلية المتعلق بمزاعم الادارة بشكل مباثر (الرقابة على التطبيقات) وهل تتوافق مع التقييم المبدئي لها في مرحلة التخطيط أما أذا نتج عن هذه الاختبار ات وجود ضعف في نظام الرقابة الداخلية يقوم المدقق بأعادة النظر في التقييم المبدئي لخطر الرقابة الداخلية ومن

$$
\text { ثم تغيير مدى الاختبار ات الجو هرية وطبيعتها. }
$$

ب- الاختبار ات الجوهرية : تتم هذه الاختبار ات من طريق اجراءات تحليلية وينم ذلك من خلال اجر اء تقييم للنتائج التي توصل اليها المدقق من الاجراءات التحليلية للتعرف على حالات الغش المحتملة وكذلك تتضمن الاختبارات الجوهرية اختبارات تفاصيل العمليات والارصدة , تهدف الى الحصول على ادلة اثبات نؤيد صحة التصنيف والترحيل والافصاح لجميع العمليات التي يقوم بها نظام المعلومات المحاسبي الالكتروني للمنشأة .

ـ - مرحلة التقرير : وهي اخر مر احل عملية التذقيق ومنه يقوم المدقق بتجميع الأدلة وتقييمها واستخلاص النتائج للتأكد أن مستوى خطر التدقيق عند حده المقبول أو بالعكس ثم يقوم بأعداد التقرير الذي يعبر عن رأي المدقق وذلك بأستخدام

[3] امج التدقيق الالكتروني للبيانات ـ الاعتبار ات في استخدام اساليب التدقيق الالكتروني

[4]: هناك العديد من الاعتبار ات يجب مر اعاتها عند استخدام اساليب التدقيق الالكتروني يمكن ايجاز ها بالآتي 1- معرفة و اطلاع وخبرة المدقق بتقنية المعلومات .

r- توفر أساليب التدقيق بمساعدة الحاسب الالي و المر افق الحاسوبية المناسبة . r- عدم كون الاختبار ات اليدوية عملية . ع- الفاعلية و الكفاءة ثانيا : اجراءات التذقيق الالكتروني هناك العديد من الاجر اءات يتوجب توفرها في ظل التذقيق الالكتروني : 1- المهارة و الكفاءة: حيث يجب أن تتوفر المهارة والكفاءة اللازمة لمدقق الحسابات عند قيامه بالتدقيق الاككتروني للبيانات r- التخطيط لعملية التنقيق: حيث يجب مر اعاة جميع الامور ذات الصلة بعملية التتقيق عند القيام بتصميم برامج التتقيق لضمان نجاح العملية. 
r- تقدير المخاطر : تمشيا مع معيار التدقيق الدولي رقم ( . . ) الخاص بنقدير المخاطر والرقابة الداخلية, حيث يجب على المدقق أن يقوم بعمل تقدير للمخاطر الملازمة ولمخاطر الرقابة لضمان سلامة العمليات. المبحث الثاني : مخاطر التنقيق وتكنولوجيا المعلومات

قبل التعرف على مخاطر التدقيق وتكنولوجيا المعلومات لابد من التعرف على ماهية الخطر ومكوناته بشكل عام ثم يتم

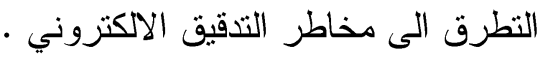
1- ماهية خطر النذقيق

لقد نم تعريف الخطر من قبل العديد من الكتاب فقد عرفه مجمع المحاسبين القانونيين الامريكي بأنه " الخطر الذي

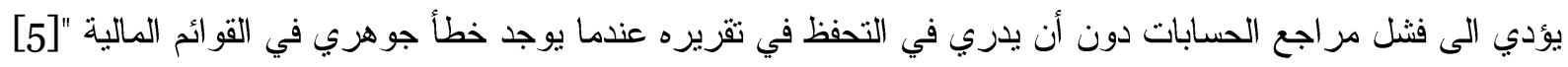

كما عرف بأنه "احتمال أبداء راي غير سليم في القوائم المالية موضع الفحص وذلك بسبب فثل مر اقب الحسابات

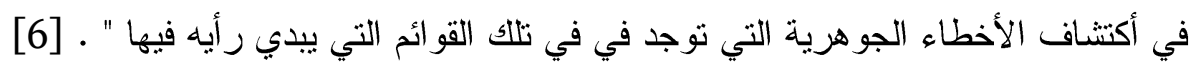
من التعريفين اعلاه نستنتج بأن خطر التدقيق هو الخطر الناتج عن الفشل في تحديد الأخطاء الجوهرية في البيانات المالية مما يؤدي الى ابداء المراجع لر أي غير صحيح في القو ائم المالية .

يعتبر خطر التذقيق من العوامل المهمة التي ينبغي على المدقق أخذها بعين الأعتبار عندما يقوم بالتخطيط لعملية التذقيق وكذلك عند تقييم أدلة التدقيق حيث أن مجمع المحاسبين القانونيين الأمريكي أكد على أنه يجب على الددققين التخطيط لعملية التققيق بحيث تكون مخاطرها عند ادنى حد ممكن ومناسبا لأبداء راب سليم في مدى عدالة القو ائم المالية , وقد ينم تقدير المخاطرة بصورة كمية في صورة نسبة أو كحد معين يقع بين حد اقصى وحد ادنى . مكونات خطر التدقيق

أ-الخطر الملازم : وهو قياس لتقدير المراجع لأحتمال وجود أخطاء جوهرية في مجموعة معينة من العمليات قبل

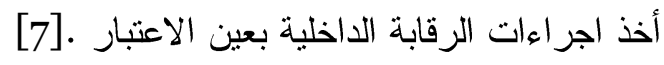

و هناك منَ أثشار الى أن الخطر الملازم هو قابلية رصيد معين أو نوع معين من العمليات للخطأ الذي يكون جوهريا

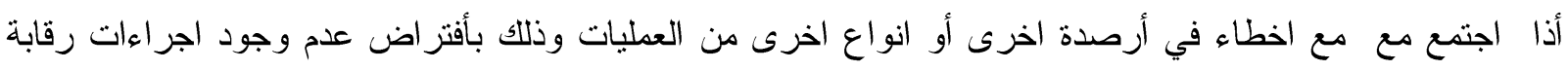

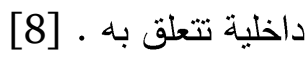
ب- خطر الرقابة : وهو قياس لتقفير المراجع لأحتمال اكتثاف الأخطاء التي تتجاوز الحد المقبول في مجموعة معينة من البيانات في الوقت المناسب من قبل نظام الرقابة الداخلية . 
ج- خطر الأكتشاف المخطط : هو الخطر الناتج عن فثل ادلة التنقيق في اكتشاف الأخطاء التي تتجاوز الأخطاء المقبولة في مجموعة معينة من البيانات , ويعتمد المدقق على وجود الخطر الملازم وخطر الرقابة عند وجود خطر الأكتشاف أي أنه في حالة وجود خطر الاكتشاف على المدقق البحث عن الخطر الملازم وخطر الرقابة , ويقسم خطر الأكتشاف الى خطر التدقيق التحليلي وخطر التذقيق التفصيلي.

ويرتبط مستوى مخاطر الأكتشاف بالأجراءات التي يطبقها مدقق الحسابات , ويؤثر تقييم مخاطر الرقابة والمخاطر

[9] الملازمة على طبيعة وتوقيت ومدى الأجر اءات المطبقة للتقليل من مخاطر الأكتشاف بالهزئ r- مخاطر التدقيق وتكنولوجيا المعلومات

[10]: توجد العديد من المخاطر المؤثرة على اجراءات التدقيق يمكن تصنيفها بالآتي 1- مخاطر ناجمة عن البنية التحتية لتكنوجيا المعلومات . r- مخاطر ناجمة عن تطبيقات تكنولوجيا المعلومات . ب- مخاطر ناجمة عن عمليات الاتصال . 1- مخاطر ناجمة عن البنية التحتية لتكنوجيا المعلومات : تتمثل هذه المخاطر بالاتي : 1- ا- عدم مناسبة اجر اءات الأمن الطبيعية لمنع السرقة والوصول غبر المشروع أو الافصاح غبر الملائم للمعلومات. ا I-r- التعرض لدرجة الحرارة العالية والكوارث الطبيعية . 1-r- (1- عدم كفاية خطة الطو ارىء.

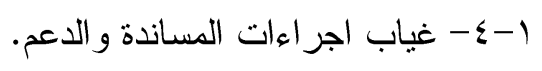

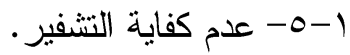
ץ- مخاطر ناجمة من تطبيقات تكنولوجيا المعلومات : ينجم هذا النوع من المخاطر بسبب الآتي: r-1- وجود مشاكل و أخطاء في تطبيقات تكنولوجيا المعلومات.

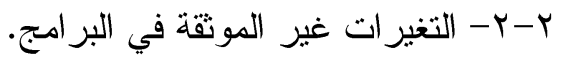
r-r- عدم كفاية ضو ابط الادخال و المعالجة و الاخر اج المصممة بشأن تطبيقات تكنولوجيا المعلومات. ץ-乏- عدم كفاية إجر اءات تأمين أمن البرامجيات المتصلة بأمن البنية التحتية لتكنولوجيا المعلومات. 
Journal of University of Babylon for Pure and Applied Sciences,Vol.(26), No.(7): 2018

r- مخاطر ناجمة عن عمليات الاتصـال: تتمثل هذه المخاطر بالآتي :

ب-1 - مخاطر العتاد ونشمل

ب-1-1- السرقة أو التعطيل أو التحريف.

$$
\begin{aligned}
& \text { ץ-1- ז- عمل نسخ من مفاتيح الدخول للنظم و المو اقع. }
\end{aligned}
$$

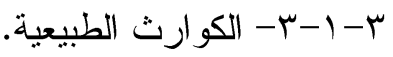

$$
\begin{aligned}
& \text { r-1-ع - أخطاء في ادارة العتاد. } \\
& \text { r-r- مخاطر البرمجيات وتشمل }
\end{aligned}
$$$$
\text { r-r-1- دخول غير مشروع الى مواقع الحاسبات }
$$

r-r-r- سرقة البيانات و المعلومات كالتصنت و التصفح.

r-ץ-ץ- أخطاء اثثاء عمل البرمجيات.

$$
\text { r-Y-乏- نشر معلومات عبر قنوات الاتصال. }
$$

الفصل الثاني : مفهوم جودة التدقيق الخارجي وأهميته

\section{مفهوم جودة التدقيق}

لقد تعددت التعاريف التي تتاولت مفهوم جودة التدقيق نظر ألتعدد الاطر اف المستقيدة من التدقيق من حيث علاقتها بمدى مقدرة المدققين على اكتشاف الاخطاء و المخالفات في القوائم المالية للمنشآة محل التطبيق .

حيث عُرف أحد الباحثين جودة التدقيق على انها " عملية التدقيق بكفاءة وفعالية وفقا للمعايير المهنية للتدقيق وقو اعد و آداب السلوك المهني الصادرة عن المنظمات المهنية وضوابط رقابة الجودة مع الأفصاح عن الأخطاء والمخالفات

المكتشفة بما بحقق للأطر اف ذات الصلة الأهداف المتوقعة من عملية التدقيق" [11]

و هناك من عرف جودة التدقيق على انها " اكتشاف المدقق للأخطاء والثغرات في النظام المحاسبي وتقليل خطر وجود الأخطاء في القو ائم المالية إلى ادنى حد ممكن [12] 
أن جودة التدقيق تتطلب تدنية المدقق لخطر الأكتشاف والذي يؤدي الى تدنية خطر التدقيق ويرى النهائي والافصاح عن [13]. الاخطاء الجوهرية في القوائم المالية

ومن التعاريف اعلاه يتضح لنا أن المدقق اذا ماقام بتخطيط عطية التذقيق على اساس دراسة العوامل المؤثزة في الخطر وحدد مناطق الخطر واخذها في الأعنبار عند القيام بكل اجراء من اجراءات التدقيق ثم استخدم الأجراء الذي يتتاسب مع طبيعة العنصر ومسنوى الخطر المعرض له فأن ذلك يدعم رأي المدقق في القوائم المالية ويؤدي الى تحقيق الكفاءة و الفعالية لعملية التذقيق ويترتب عليه ندنية المخاطر إلى الحد الادنى الذي يمكن قبوله .

ولا شك أن القيام بعملية التدقيق على هذا النحو من شأنه أن يرفع الكفاءة المهنية للمدقق ويؤدي الى زيادة جودة التدقيق نفسها من خلال تحسين الرأي الذي يبديه المدقق في القو ائم المالية .

أهمية جودة التدقيق: تكمن أهمية جودة التدقيق في انها مطلب جميع مستخدمي القو ائم المالية وذلك للأسباب التالية : ا- يهدف المدقق من تتفيذ عملية التدقيق بأعلى جودة ممكنة حتى يضفي أعلى درجات المصداقية على تقريره. ץ- تسعى المنشأة الى تأكيد تمتع قو ائمها المالية بالموثوقية , مما يوجب القيام بعملية التدقيق بأعلى مسنوى من الجودة . ب- ترى المنظمات المهنية أن تتفيذ عملية التذقيق بأعلى مستوى من الجودة يحقق المصلحة لجميع مستخدمي القوائم المالية ع- تمثل جودة مهنة التتقيق مقياسا لتقييم مكاتب التنقيق في ظل المنافسة الثديدة بين تلك المكاتب. عناصر الرقابة على جودة التدقيق تتمنل عناصر جودة التدقيق بالآتي : [14] 1- الاستقلال: وهو يعني وضع مايلزم من السياسات والاجراءات التي تؤكد بشكل معقول تمتع اعضاء مكتب التذقيق بالاستقلال من الناحيتين الذهنية و الموضوعية .

ץ- تخصيص الافراد بالمكتب على الوظائف المختلفة للتدقيق بما بضمن أن المهمة المناسبة للشخص المناسب ابي المهيأ علمياً وعملياً . تحنياً

س- طلب المشورة أي وضع السياسات والاجراءات اللازمة لتنظيم طلب المشورة أو الاسترشاد برأي ذوي الخبرة وذلك لضمان فيام المدققين بطلب المشورة فيما يعترضهم من مشكلات في عمليات التدقيق التي تتاط بهم. ع- الاشر اف ينبغي على مكتب التدقيق وضع السياسات و الاجر اءات فيما يتعلق بسير العمل و الاشراف عليه وذلك لضمان تأدية العمل بما يتو افق مع معايير الجودة . 
ه- التوظيف : ويشير الى وضع سياسات واجراءات تكفي لتوفير تأكيد معقول أن الموظفين بسمات ملائمة تمكنهم من أداء

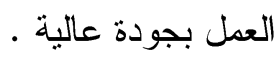

צ- تتمية القدرات المهنية : أي التأكد من تمتع الدوققين في مكتب التدقيق بالمعرفة اللازمة للقيام بأعمالهم بالأضافة الى

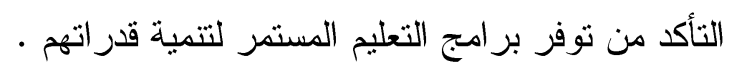

V- الفحص الدوري : أي وضع مايلزم من السياسات والاجراءات للتأكد من فعالية الاجراءات الخاصة بضمان جودة الممارسات المهنية لمكتب التدقيق .

[15] مقاييس جودة التدقيق :قسمت در اسة باعجاجة مقاييس جودة التدقيق الى مايلي

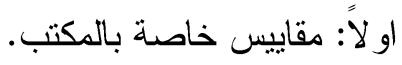
ثانيا: مقاييس خاصة بفريق العمل.

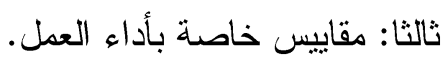
رابعا: مقاييس خاصة بالعملاء. او لا: مقاييس خاصة بالمكتب وتثمل ( توفر وسائل الثقنية الحيثة وتنظيم المكتب اداريا). ثانيا: مقاييس خاصة بفريق العمل وشمل ( التوظيف, التنريب و الترقية ) . ثالثا : مقاييس خاصة بأداء العمل وتثمل (الأثراف و التوجيه, المشورة, الاستقلال, تخصيص المساعدين للعمليات , الالتز ام بمعايير المحاسبة و التنقيق والالتز ام باداب وسلوك المهنة). رابعا : مقاييس خاصة بالعملاء وتشمل ( تقييم العملاء الجدد قبل التعاقد معهم والاستمرار في التذقيق للعملاء الحاليين مع

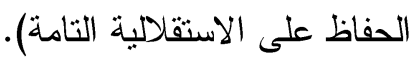
العوامل المؤثرة على جودة التدقيق الخارجي: هناك العديد من العوامل التي تؤثر في جودة التدقيق الخارجي منها مايلي : 1- حجم مكتب التّقيق: حيث نتثير الدراسات إلى أن الدكاتب التي تسيطر على اكبر حصة في السوق نعتبر اكثر جودة. r- السمعة او الثهرة الحسنة لمكتب التدقيق: حيث أن المكتب ذو السمعة الجيدة يحرص على نوظيف مدققين ذوي كفاءة وخبرة عالية ليعزز ويحافظ على مكانته بين مكاتب التدقيق الاخرى يعتبر هو الأفضل. 
ب- عدم وجود دعاوي قضائية مرفوعة على مكتب التدقيق : اذ يجب على مدققي الحسابات الالتزام بتطبيق المعايير المهنية لتدقيق الحسابات وقو اعد السلوك المهني ومراعاة الأنظمة و القو انيين عند القيام بفحص القو ائم المالية تجنبا للجوء إلى اقامة الدعاوي القضائية من قبل العملاء] ع- التزام مكتب التدقيق بالمعايير المهنية : تتميز مهنة التدقيق بأنها تؤدى من قبل اشخاص مؤهلين, مدربين, مستقلين ومحايدين ومسؤولين مهنيا و السبيل للحفاظ على ذلك هو معايير التدقيق المتعارف عليها فهي تعتبر مستويات مهنية لضمان التز ام المدقق ووفائه بمسؤولياته .

0- وجود نظام رقابة على جودة الاداء: حيث بينت الفقرة الر ابعة من المعيار الدولي للتنقيق رقم •rr ( أنه ينبغي على مكتب التدقيق تتفيذ سياسات واجر اءات رقابة الجودة والتي صمدت للتأكد بأن كافة عمليات التدقيق قد تمت حسب المعايير الدولية للتذقيق او المعايير الوطنية المناسبة).

7- الخبرة المهنية لمكتب الندقيق: تؤثر الصفات الثخصية لفريق التدقيق على جودة التدقيق بشكل أساسي, ومن اهم هذه الصفات ذات الأثز الكبير على عملية التقدير الثخصي و أصدار الاحكام في التدقيق الخبرة المهنية لفريق التدقيق .

V- خبرة مكتب التدقيق في المجال المهني الذي ينتمي اليه العميل : إن مدققي الحسابات بسعون إلى فهم المجال المهني الذي ينتمي اليه العميل لما له من أثز على زيادة مقدرتهم في مجال اكتشاف الأخطاء والاحتيال المالي في القوائم المالية حيث أن استخدام استراتيجية التخصص المهني للمدقق الخارجي يؤثر على جودة التدقيق • 1 طول مدة ارتباط المدقق : أي طول مدة ارتباط المدقق بالمنشأة التي يقوم بتدقيق حساباتها وعدد السنوات التي يقوم المكتب خلالها بتدقيق القوائم المالية لذات المنشأة وقد أثنارت الدراسات إلى أن الفترة الطويلة لعمل المدقق [17] [الخارجي في تدقيق ذات المنشأة من شأنه أن يخفض من جودة التدقيق الخارجي 9- استقلال مكتب التذقيق : يمثل استقلال مكتب التدقيق احد معايير التذقيق المتعارف عليها , وطبقًا لهذا المعيار يجب على المدقق الحفاظ على استقلاله في كافة النواحي مما يعني عدم ابداء رأياً أو حكماً مهنياً في المنشأة إلا أن يكون مستقلا عنه

• 1- تقيم مكتب التدقيق الخدمات الاستشارية لعميل التدقيق: إن تقديم مكتب التذقيق الخدمات الاستشارية لعملائهم يؤثر سلبا على جودة التدقيق , لأن تقديم منل هذه الخدمات يؤدي لاعتماد المدققين على عملائهم مادياً مما يضعف صلابتهم أمام زيارة المنشأة ويهدد موضوعيتهم عند القيام بعملية التدقيق.

الا- أتباع الاساليب الحديثة في التذقيق : تهنم مكاتب التدقيق بالحصول على المؤهلات العلمية و العملية التي تؤدي إلى تحسين قدر اتهم المهنية وذلك بهدف الارتقاء بمستوى جودة الأداء المهني للتنقيق. 
ب ا - الأهمية النسبية لأجور التدقيق : حيث اظهرت الدراسات أن انخفاض أجور التدقيق يؤدي الى عزوف المهنيين عن المهنة وعدم اجنذاب الكفاءات المهنية للعمل المذكور خاصة في المكاتب الصغيرة مما يجعلها أكثر تعرضا واستعداداً [18]. لمسايرة الاوضاع

نستتنج مما سبق أن هناك العديد من العوامل التي تؤثر على جودة التدقيق ينبغي مراعاتها لما لها من أثر كبير على صحة القوائم المالية وسلامتها الامر الذي ينعكس على عملية اتخاذ القرار لجميع المستخدمين و المستفيدين من تلك القوائم .

الجانب النطبيقي: يتكون مجتمع الدراسة من مدقي الحسابات للمنطقتين الوسطى والجنوبية , حيث نم توزيع استمارة الاستبانة البالغ عددها (.0) استمارة وتم استرداد ( سك) استمارة فقط , و الجدول رقم (1) يوضح توزيع عينة الدراسة

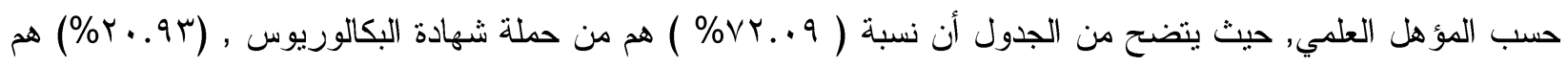
من حملة شهادة الماجستير , ( 1 . \% \% ) هم من حملة الثهادات الأخرى (المعهد العربي) اما بالنسبة لشهادة الدكتور اه فلا يوجد شخص يحملها حسب عينة الدر اسة ويمكن توضيح ذلك بالجدول ادناه .

جدول رقم ( 1 ) يوضح توزيع عينة الدراسة حسب المؤهل العلمي

\begin{tabular}{|c|c|c|}
\hline النسبة المئوية & التكرار & المؤهل العلمي \\
\hline VY. . 9 & ו & بكالوريوس \\
\hline$r \cdot .9 r$ & 9 & ماجستير \\
\hline---- & ---- & دكتور اه \\
\hline 7.91 & $r$ & اخرى \\
\hline $1 \ldots$ & $\varepsilon r$ & المجموع \\
\hline
\end{tabular}

وقد تم توزيع عينة الدراسة حسب العمر بالسنوات في الجدول رقم (r) , ويتضح من الجدول أن نسبة (70.؛\%)

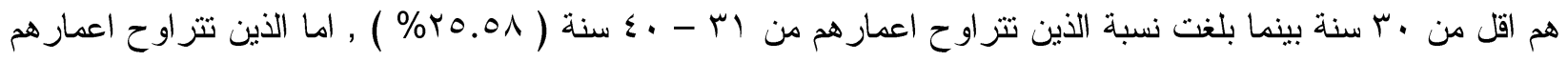
من اء - .0 سنة فبلغت نسبتهم (90.ب(\%) وقد كانت النسبة الأكبر للذين هم اكثر من (.0 سنة) حيث بلغــت نسبتهم

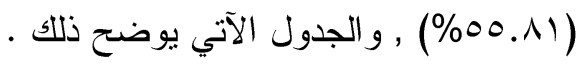

جدول رقم ( r ) يوضح توزيع عينة الدراسة حسب العمر بالسنوات

\begin{tabular}{|c|c|c|}
\hline النسبة المئوية & التكرار & العمر بالسنوات \\
\hline$\$ .70$ & r & اقل من ابس سنة \\
\hline Y0.01 & 11 & ا - - • ع سنة \\
\hline 15.90 & 7 & إ - .0 سنة \\
\hline
\end{tabular}


Journal of University of Babylon for Pure and Applied Sciences,Vol.(26), No.(7): 2018

\begin{tabular}{|c|c|c|}
\hline 00.11 & $r \leqslant$ & 0. \\
\hline $1 . .$. & سنة فأكثر & (المجموع \\
\hline
\end{tabular}

وقد تم نوزيع عينة الدر اسة حسب الخبرة في مجال التدقيق في الجدول رقم (r) و اتضح من الجدول المذكور أن نسبة (0.؛؛\%)

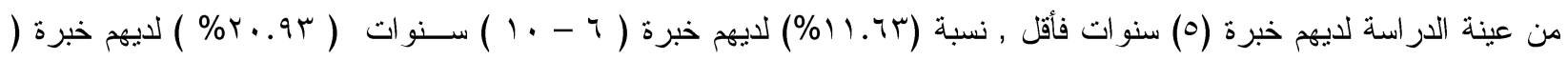

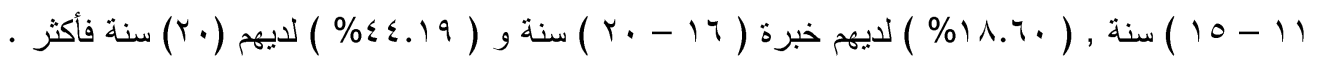

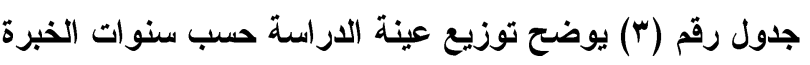

\begin{tabular}{|c|c|c|}
\hline النسبة المئوية & 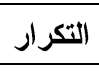 & عدد سنوات الخبرة في مجال التثقيق \\
\hline 5.70 & r & ه سنو ات فأقل \\
\hline אז. 11 & 0 & من ד - . ا سنوات \\
\hline$r \cdot .9 r$ & 9 & من 11 - 10 سنة \\
\hline $1 \wedge .7$. & $\wedge$ & من 17 - . r سنة \\
\hline$\leq \leqslant .19$ & 19 & • r سنة فأكثر \\
\hline $1 \ldots$ & हा & المجموع \\
\hline
\end{tabular}

وقد تم تقسيم محاور الاستبانة على أربعة محاور وكما يلي : المحور الاول: مخاطر البنية التحتية لتكنلوجيا المعلومات ـ ( • فقرات) المحور الثاني: مخاطر تطبيقات تكنولوجيا المعلومات ـ (• فقرات) المحور الثالث: مخاطر عمليات الاتصال ـ ( ا(فقرة ) المحور الرابع: جودة التدقيق وينقسم الى المحاور الفرعية الآتية : 1- جودة الخدمة (ع فقرات), r- جودة المدقق (ع فقرات) , r- جودة التقرير (0 فقرات) , ع- جودة اداء العمليات (0 فقرات) ه- استقلال المدقق (ع فقرات) .

وقد كانت الاجابات على مقياس ليكارت الخماسي وكما موضح في الجدول رقم (ء) 
Journal of University of Babylon for Pure and Applied Sciences,Vol.(26), No.(7): 2018

\begin{tabular}{|r|r|r|r|r|r|}
\hline 1 & $r$ & $\varepsilon$ & 0 & التصنيف| \\
\hline
\end{tabular}

علماً أند قد نم عرض الاستمارة على مجموعة من المحكمين وقد نم حساب صدق الاتساق البنائي لمحاور الدراسة وكما موضح في الجدول رقم (0) و الذي يبين معاملات الارتباط بين معدل كل محور من محاور الدراسة مع المعدل الكلي لفقزات الاستبانة , وقد تبين أن معاملات الارتباط المبينة دالة عند المستوى (0. . ) , حيث ان القيمة الاحتمالية لكل فقرة اقل من (0. . •) وقيمة (R) المحسوبة اكبر من قيمة R) الجدولية و التي تساوي (Tوس. •).

جدول رقم (ه) يبين معامل الارتباط بين معدل كل محور من محاور الاراسة مع المعدل الكلي لفقرات الاستبانة

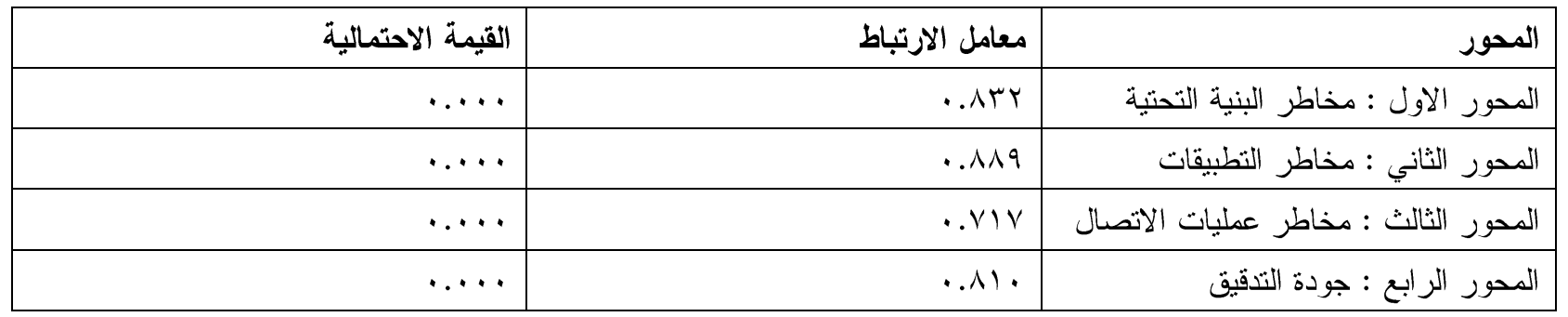

وقد تم استخدام اختبار (t) للعينة الو احدة لتحليل فقرات الاستبانة .

وتكون الفقرة ايجابية بمعنى أن افراد العينة يواققون على محتواها اذا كانت قيمتها المحسوبة اكبر من الجدولية والتي تساوي (Y . r. و وتكون الفقرة سلبية بمعنى أن افراد العينة لا يو افقون على محتواها اذا كانت قيمتها المحسوبة اقل من الجدولية والتي تساوي (- r ... وتكون الار اء محايدة اذا كانت القيمة الاحتمالية اكبر من هـ ... .

تحليل فقرات المحور الاول : مخاطر البنية التحتية

تن استخدام اختبار (t) للعينة الواحدة والنتائج المبينة في الجدول رقم (T) و الذي يبين اراء افراد عينة الدراسة في فقرات

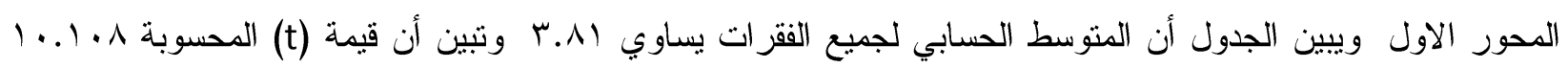

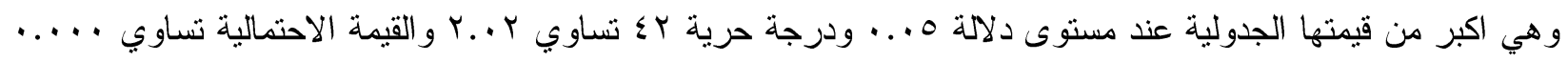

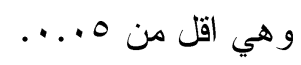


جدول رقم (؟) يبين تحليل فقرات المحور الاول ( مخاطر البنية التحنية)

\begin{tabular}{|c|c|c|c|c|c|}
\hline الإحتمالبة & t قيمة & الانحر اف & المتوسط الحسابي & 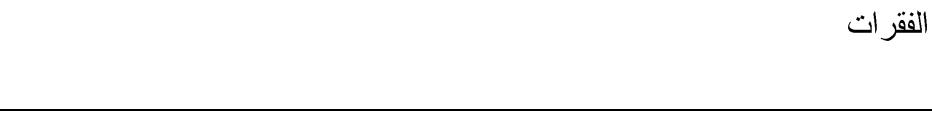 & $ت$ \\
\hline$\cdots \cdots$ & $11 . \cdot \wedge \Lambda$ & $\cdot 7 \wedge \wedge$ & $\varepsilon .17$ & عدم مناسبة اجر اءات الأمن والوقاية يسهم في التأثير على مخاطر البنية التحنية & 1 \\
\hline$\cdots \cdots$ & $\wedge . \leqslant 19$ & $\cdot 110$ & $\varepsilon .0$ & تؤثز الظروف الطبيعية ( الموسمية ) في مخاطر البنية التحتية & r \\
\hline$\cdots \cdots$ & r.var & $\cdot . \wedge \vee \leqslant$ & r.re & تغيير خطة الطور ایه الخاصة بنظم المعلومات يؤثز بمستوى مخاطر البنية التحتية & r \\
\hline$\cdots \cdots$ & $v_{\cdot} \cdot \leqslant 0$ & $\cdot . \wedge r$ & $r . \wedge \wedge$ & التأكد من نوفر اجر اءات المساندة والدعم يسهم في التأثير على مخاطر البنية التحنية & $\varepsilon$ \\
\hline$\cdots \cdots$ & $9.0 . r$ & $\because 79$ & $\varepsilon \ldots$ & عدم كفاية التثفير اللازم يزيد من مخاطر البنية التحنية & $\circ$ \\
\hline$\cdots \cdots$ & 0.111 & $\cdot .170$ & r.TV & يتغير مستوى مخاطر البنية التحنية حسب طبيعة نشاط المنشأة . & 1 \\
\hline$\cdots \cdots$ & 7.600 & 0.762 & 3.88 & يؤثز حجم المنشأة في مخاطر البنية التحتية & $\checkmark$ \\
\hline$\cdots \cdots$ & 4.684 & 0.944 & 3.67 & طبيعة عمليات المنشأة تؤثر في مخاطر البنية التحتية & $\wedge$ \\
\hline$\cdots \cdots$ & $\leqslant . \cdot \leqslant 9$ & $\cdot .9 \vee 9$ & r.7. & تشكل طبيعة الأخطاء المتوقع اكتشافها عاملاً مؤثر اً في مخاطر البنية التحتية & 9 \\
\hline$\cdots \cdots$ & .9119 & $\cdot V \leqslant r$ & r.va & التأكد من معقولية التقدير ات المحاسبية يخفض مخاطر البنية التحتية & 1. \\
\hline$\cdot \ldots$ & $1 \cdot .1 \cdot 1$ & .0 Yo & r.A & جمع الفقرات] & \\
\hline
\end{tabular}

ومن الجدول أعلاه نلاحظ أن عدم مناسبة اجراءات الأمن والوقاية يؤثز بشكل كبير على مخاطر البنية التحتية مها يتطلب الاهتمام بذلك حيث كان المتوسط الحسابي للفقرة المذكورة (17 .ـ) وهو اعلى المتوسطات قياسا بالفقرات الاخرى. تحليل فقرات المحور الثاني (مخاطر التطبيقات)

تم استخدام اختبار (t) للعينة الواحدة والنتائج المبينة في الجدول رقم (V) و الذي يبين آراء أفراد عينة الدراسة في فقرات المحور الاول ويبين الجدول أن المتوسط الحسابي لجميع الفقرات يساوي 9V. و وتبين أن قيمة (t) المحسوبة هبه.با وهي اكبر من قيمتها الجدولية عند مستوى دلالة ه... ودرجة حرية rع تساوي Y... و القيمة الاحتمالية تساوي . ... . . هي اقل من ه.. . . 
جدول رقم (V) يبين تحيل فقرات المحور الاول ( مخاطر التطبيقات )

\begin{tabular}{|c|c|c|c|c|c|}
\hline الاحتمالية & t قيمة & المعياري & الحنو سط الحسبي & 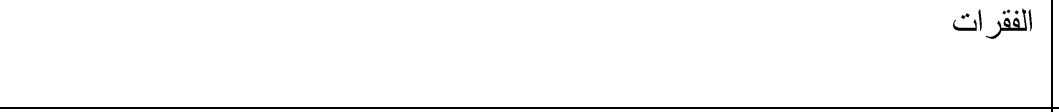 & $ت$ \\
\hline$\cdots \cdots$ & $\varepsilon .7 \wedge \varepsilon$ & $.9 \varepsilon \varepsilon$ & r.T & | تستخدم تكنلوجيا المعلومات في المنشأة بفاعلبة وكفاءة & 1 \\
\hline$\cdots \cdots$ & $V . Y \wedge \varepsilon$ & $\cdot v \circ \leq$ & $r . \wedge \varepsilon$ & | وجود اخطاء في تطبيقات تكنلوجيا المعلومات يسهج في رفع مخاطر التطبيقات & r \\
\hline$\cdots \cdots$ & $10 . \leqslant \leqslant 9$ & $.0 \vee r$ & s.ro & يتأثز مستوى مخاطر التطبيقات بوجود كفاءة وفاعلية في استخدام تكنلوجيا المعلومات & r \\
\hline$\cdots \cdots$ & $\varepsilon . \varepsilon \vee \uparrow$ & $\cdot .10 \mathrm{r}$ & r.01 & كفاءة عمليات الادخال و المعالجة والاخر اج تؤثر في تخفيض مخاطر النطبيقات & $\varepsilon$ \\
\hline$\cdots \cdots$ & 15.179 &. .011 & צ.Y & | التغيير غير الموثق للبر امج يسهم في زيادة مخاطر التطبيقات & ० \\
\hline$\cdots \cdots$ & $\vee .7 \ldots$ & $\begin{array}{r}\cdots \\
r\end{array}$ & 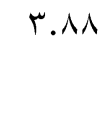 & تحليل البيانات التي توفرها تكنلوجيا المعلومات يساعد في تخفيض مخاطر التطبيقات & 7 \\
\hline$\cdots \cdots$ & V.voq & $\cdot \wedge \leqslant 0$ & $\varepsilon \ldots$ & |التطبيقات & V \\
\hline$\cdots \cdots$ & $\Lambda .94$. & $\cdot \wedge \wedge \wedge$ & $\{. Y)$ & فعالية وكفاءة اجر اءات حماية البر امج الخاصة بتكنلوجيا المعلومات يقلل من مخاطر & $\wedge$ \\
\hline$\cdots \cdots$ & $\Lambda .194$ &. .107 & $\varepsilon . \cdot V$ & | فعالية اجر اءات أنظمة الضبط الداخلي يسهم في تخفيض محاطر التطبيقات & 9 \\
\hline$\cdots \cdots$ & $1.9 r \leq$ & .710 & 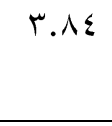 & | لتؤثر نوع البرامج المطبقة في عملية التدقيق الاككتروني في مستوى مخاطر & 1. \\
\hline$\cdots \cdots$ & Ir.oro & $\cdot \Sigma \vee \cdot$ & $r .9 V$ & 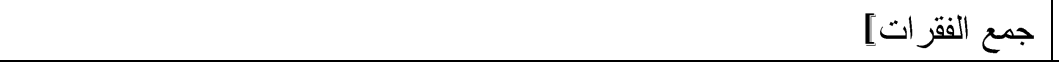 & \\
\hline
\end{tabular}

ومن الجدول اعلاه نلاحظ أن مستوى مخاطر التطبيقات يتأثر بشكل كبير بكفاءة استخدام تكنلوجيا المعلومات مما يتطلب الاهتمام بذلك حيث كان المتوسط الحسابي للفقرة المذكورة ( 0ب.ء ) وهو اعلى المتوسطات قياسا بالفقزات

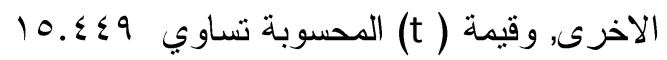

$$
\text { تحليل فقرات المحور الثالث ( مخاطر عمليات الاتصال ) }
$$

hard ware and soft ware تنظيم جدول رقم (^) لتحليل فقرات المحور الثالث والخاص بعمليات الاتصال وكما يلي : 


\section{جدول رقم ( ^) يبين تحليل فقرات المحور الثالث ( مخاطر عمليات الاتصال )}

\begin{tabular}{|c|c|c|c|c|c|}
\hline الاحنمالية & ق قيمة & 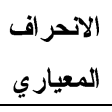 & | المستوسط & 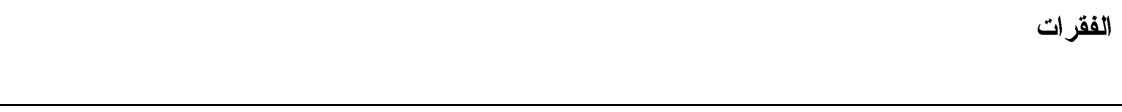 & $ت$ \\
\hline$\ldots$ & 11.794 & $.70 \mathrm{r}$ & 5.17 & سلامة اجر اءات حماية العتاد يسهم في تخفيض مخاطر عمليات الاتصال & 1 \\
\hline$\cdots$ & IY. $\varepsilon \cdot \varepsilon$ & $.7 T V$ & $\leqslant .19$ & التحقق من التطبيق السليم لأجر اءات العتاد يخفض مخاطر عمليات الاتصال & r \\
\hline$\cdots$ & 11.419 & $.7+9$ & $\leq .1 \leq$ & تلفاوت مستوى الخبرة بين المدققين يؤثز في دقة تفسير نتائج التدقيق وبالتالي مستوى مخاطر عمليات & r \\
\hline .... & $\wedge . \cdot \vee \wedge$ & 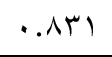 & $\varepsilon .+r$ & التأكد من بذل العناية الكافية والاهتمام يجنب حدوث الأخطاء ويؤثر في مستوى مخاطر الاتصال & $\varepsilon$ \\
\hline$\cdots$ & Ir.VIr &. $.00 \mathrm{r}$ & $\varepsilon . \cdot v$ & عمل نسخ من مفاتيح الدخول للنظم و المو اقع يقلل من مخاطر الاتصال & 0 \\
\hline$\ldots \ldots$ & $9 . \cdot 1 r$ & $.7 \wedge \wedge$ & $r .90$ & التخطيط الجيد لعملية التثقيق يقلل من مخاطر عمليات الاتصال & 7 \\
\hline$\ldots$ & $1 . .7 r \pi$ &.$V M r$ & $\leq .19$ & الدقة في تحديد نطاق عملية التدقيق يقلل من مخاطر عمليات الاتصال & $\mathrm{v}$ \\
\hline$\cdots \cdots$ & 9.911 & $\cdot \vee 1 \wedge$ & $\leq . .9$ & اختبار المساعدين بؤثر بشكل كبير في مستوى مخاطر عمليات الاتصال & $\wedge$ \\
\hline$\ldots$ & 7.1 .9 &. .101 & $r . \wedge \Lambda$ & تساعد المقارنات الزمانية للييانات بشكل كفوء وفعال في تخفيض مخاطر عمليات الاتصال & 9 \\
\hline$\cdots \cdots$ & $0.0 \vee 0$ &.$\wedge \vee 0$ & $r . \vee \leq$ & مقارنة البيانات المر اد تدقيقها مع المخطط يؤثر في مستوى مخاطر عمليات الاتصال & 1. \\
\hline$\cdots \cdots$ & $7 . .7 \mathrm{~V}$ &.$\wedge \wedge$ & $r . \wedge 1$ & يسهم اكتثاف الاخطاء الناتج من عمليات المقارنة في تخفيض عملبات الاتصال & 11 \\
\hline$\cdots \cdots$ & 纟.^V. &. .949 & r.v. & الاختبار ات التفيلية للعمليات تشهم في تخفيض مخاطر عمليات الاتصال & ir \\
\hline$\ldots$ & 14.790 &..$\leqslant \vee \wedge$ & $\varepsilon \ldots$ & 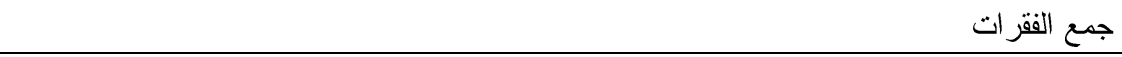 & \\
\hline
\end{tabular}

ومن الجدول اعلاه نلاحظ أن مستوى مخاطر عمليات الاتصلا يتأثز بشكل كبير بكفاءة اجراءات الحماية والامن

لعمليات الاتصسال والخاص بتتنولوجيا المعلومات مما يتطلب الاهتمام بذلك , حيث كان المتوسط الحسابي للفقرة المذكورة (9 (ـ ) و هو أعلى المتوسطات قياسا بالفقرات الاخرى , وهذا الامر يتطلب بذل العناية المهنية اللازمة واستخام اسلوب المقارنات بشكل جيد فضلا عن توفير كل مستلزمات الحماية والامان التي تمنع الوصول إلى البيانات إلاّ من قبل الاشخاص المخولين بذلك .

تحليل بيانات المحور الرابع (جودة التدقيق) جودة الخدمة : تم تتظيم جدول رقم (9) لغرض تحليل جودة الخدمة وكالآتي : 
جدول رقم ( 9 ) تحليل فقرات ( جودة الخدمة )

\begin{tabular}{|c|c|c|c|c|c|}
\hline الاحتمالية & 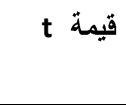 & 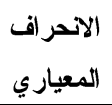 & المستوسط & الفقر ات & $ت$ \\
\hline$\cdots \cdots$ & ᄉ. $\leqslant$ T & $.9 \leqslant$ & $\left\{. r_{1}\right.$ & يقدم المدققون العون و المساعدة للعملاء فيما ينعلق بالنية التحتية الخاصة بلتطبيقات الحاسب & 1 \\
\hline$\cdots \cdots$ & $\wedge .97 \wedge$ & ת & 纟. $\leqslant$ & تفي المعلومات المفدمة من قبل المدققين الخاصة بتطييقات الحاسب بأحتياجات مستخدمي البيانات & r \\
\hline$\cdots$ & 11.05 & .74 & s.lr & خطة العمل المتكاملة الموضوعة من قبل المدققين و الخاصة بعمليات الاتصال تفي بأحتباجات مستخدمي & r \\
\hline$\cdots$ & ^... &. .190 & $\varepsilon .9$ & يجيب المدققون عن كل استفسار من قبل العملاء خاص بالتدقيق الاككتروني & $\varepsilon$ \\
\hline$\ldots \ldots$ & K... $\leqslant T$ &..$T r$. & 纟.1 $\leqslant$ & جمع الفقرات & \\
\hline
\end{tabular}

يدل تحليل بيانات المحور الخاص بجودة الخدمة الى أن تقديم خدمات المدققين للعملاء بشكل جيد يدل على جودة الخدمة

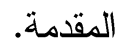

ץ- تحليل جودة المدقق: تم تتظيم جدول رقم (· ( ) لغرض تحليل جودة الخدمة وكالآتي :

جدول رقم (·1 ) تحليل فقرات ( جودة المدقق )

\begin{tabular}{|c|c|c|c|c|c|}
\hline الاحتمالية & ق قيمة t & فالانحر & الحسابي & 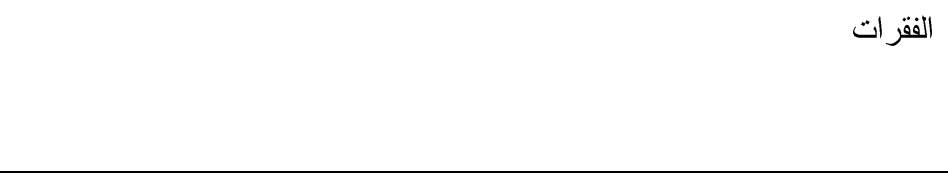 & ت \\
\hline$\cdots \cdots$ & A.rrt & $\cdot . \wedge \vee q$ & $\varepsilon .14$ & يتحلى المدققون بالأدب والاخلاق الحميدة عند اكتثافه للأخطاء مهما كان نو عها & 1 \\
\hline$\ldots$ & $11.1 \mathrm{rq}$ &. .799 & \&.19 & يتمتع المدققون بدرجة عالية من المهنية والاحتر اف فيما يتعلق بتكنولوجيا المعلومات & $r$ \\
\hline$\cdots$ & V.TI &.$\vee \wedge 1$ & $r .91$ & القدرة على اكتثاف المخالفات المالية والناتجة عن تطبيقات الحاسب & r \\
\hline$\therefore \ldots$ & 11.101 &. .710 & $\varepsilon . .0$ & حرص المدقق على متابعة معالجة المخالفات المالية أو الناتجة عن تطبيقات الحاسب & $\varepsilon$ \\
\hline$\cdots$ & Ir.r.l & $.07 \mathrm{~V}$ & $\varepsilon .+7$ & جمع الفقرات & \\
\hline
\end{tabular}

يدل تحليل بيانات المحور الخاص بجودة المدقق على أن تمتع المدققين بالأدب الرفيع والمهنية العالية يدل على جودة

المدقق وهذا ما نلاحظه من ارتفاع المتوسط الحسابي للفقرتين المذكورتين, وقيمة (t) المحسوبة اكبر من الجدولية . ץ- تحليل جودة التقرير : تم تنظيم جدول رقم ( 11 ) لغرض تحليل جودة التقرير وكالآتي : 


\section{جدول رقم (11 ) تحليل فقرات ( جودة التقرير )}

\begin{tabular}{|c|c|c|c|c|c|}
\hline الاحتمالية & ق قيمة t ق ق & فالانحر & الحسابي & 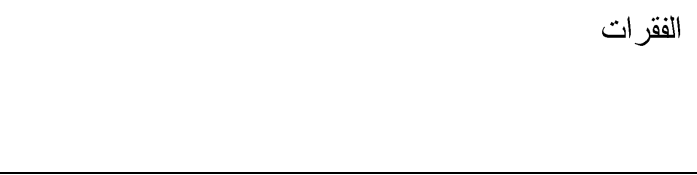 & $ت$ \\
\hline$\cdots \cdots$ & $11.11 \varepsilon$ & $\cdot v \cdot 9$ & $\varepsilon . r$ & التقة في التقارير و القو ائم المالية & 1 \\
\hline$\ldots \ldots$ & 9.187 & $\because \vee \wedge 1$ & $\varepsilon . .9$ & تفي محتويات التقارير بمنطلبات مستخدمي القو ائم المالبة & r \\
\hline$\ldots$. & $11 . .90$ & ( & $\varepsilon . \cdot V$ & تفي محتويات التقاريز بمنطلبات اصحاب القرار & r \\
\hline$\cdots \cdots$ & $\lambda . r \cdot T$ &..$V V_{1}$ & $r .91$ & يتم اعداد التقارير في الوقت المناسب & $\varepsilon$ \\
\hline$\cdots \cdots$ & $1.0 \mathrm{rV}$ & $\cdot v 1$. & 纟.1 $\varepsilon$ & تساعد تقارير المدقق في تحسين جودة التقارير المالية للمنشأة & 0 \\
\hline$\ldots$ & IT.VAT & . & 纟.1. & جمع الفقرات & \\
\hline
\end{tabular}

يدل تحليل بيانات المحور الخاص بجودة التقرير على أن الثقة في الثقارير والقو ائم المالية بدل على جودة التقرير و اعتماده اساس في عملية اتخاذ القرارات وكما مبين في الفقرة الاولى من المحور المذكور حيث احتلت اعلى المتوسطات وقيمة (t) المحسوبة فيها اكبر من الجدولية.

ع - تحليل جودة اداء العمليات : تم تنظيم جدول رقم (Y () لغرض تحليل فقرات جودة اداء العمليات .

جدول رقم (r ا ) تحليل فقرات ( جودة اداء العمليات )

\begin{tabular}{|c|c|c|c|c|c|}
\hline الاحتمالية & قيمة t ق ق ق & فالانحر ا & الحسابي & 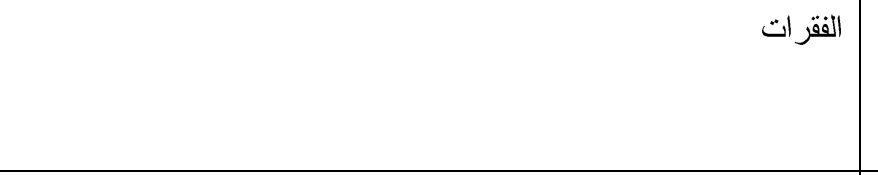 & $ت$ \\
\hline$\cdots$ & $11.7 \%$ & $\cdot . V \leqslant \vee$ & rr & يحرص مكتب التدقيق على استمر ار الاتصال و التو اصل مع العملاء & 1 \\
\hline$\cdots$ & Q.r.V & $\cdot . \wedge \uparrow \wedge$ & ז.r & يحتفظ مكتب التدقيق بسجلات دقيقة ومنظمة لعمله & r \\
\hline$\ldots$ & $1 \cdot . \leqslant \wedge 1$ &. .779 & $\varepsilon . \cdot v$ & يلتزم مكتب التدقيق بالوقت المحدد المعطى للعملاء لتتفيذ العمل المتفق عليه & r \\
\hline$\cdots \cdots$ & V.AVr &.. AVY & s..० & تؤثر قرار ات المدققين في جودة اداء العمليات & $\varepsilon$ \\
\hline$\cdot \ldots$ & $1 \cdot . \leqslant 10$ &..$\top \wedge \varepsilon$ & $\leq . .9$ & شعور العملاء بالتقة والأمان بأعمال التدقيق & $\circ$ \\
\hline$\cdot \ldots$ & $|r .49|$ & .710 & $\leqslant .10$ & جمع الفقرات & \\
\hline
\end{tabular}

يدل تحليل بيانات المحور الخاص بجودة اداء العمليات على أن ادامة الاتصال و التواصل مع العملاء تعتبر من العناصر

الرئيسية لجودة اداء العمليات يث احنلت اعلى المنوسطات وقيمة ( t ) المحسوبة فيها اكبر من الجدولية .

ع- تحليل فقرات استقلال المدقق : تم تنظيم جدول رقم ( سا ) تحليل الفقرات المذكورة . 
جدول رقم (r ا ) تحليل فقرات (استقلال المدقق)

\begin{tabular}{|c|c|c|c|c|c|}
\hline الاحتمالية & قيمة t ق & فالانحر ا & الحسابي & 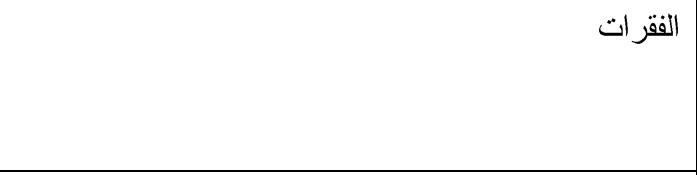 & $ت$ \\
\hline$\ldots$ & $1 . .01$ & $.70 \mathrm{r}$ & $\varepsilon . .0$ & يتقهم المدققون مشكلات العملاء ويظهرون اهتماما كافيا & 1 \\
\hline$\cdots \cdots$ & $7 . \vee 11$ & $\cdot . \vee 9 \leq$ & $r . \wedge 1$ & يحرص المدققون على توفير الاهتمام الثخصي للعميل & r \\
\hline$\cdot \ldots$ & $9.7 \ldots$ &.$V 7 r$ & s.lt & يحرص المدققون على بذل الجهد الكافي لاكتثاف الاخطاء & r \\
\hline$\cdots \cdots$ & r.var & $1 \ldots 7$ & $r .01$ & يحصل المدققون على الدعم الكافي من الادارة للقيام بأعمالهم & $\varepsilon$ \\
\hline$\cdots \cdots$ & $9.19 r$ & .970 & r.^9 & جمع الفقر ات & \\
\hline
\end{tabular}

يدل تحليل بيانات الدحور الخاص باستقلال المدقق على أن بذل الجهد الكامي من قبل المدققين يعتبر من أهم العناصر

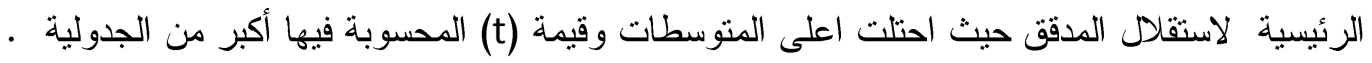

ومن تحليل فقرات المحور الرابع يتضح ارتباط كل عنصر من عناصر جودة الخدمة وجودة المدقق وجودة النقرير وجودة أداء العمليات واستقلال الدققق بجودة التنقيق بشكل عام وارتباط الفقرتين الخاصتين بجودة الخدمة وجودة التدقيق

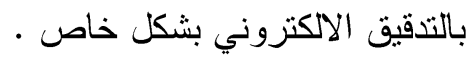

وقد تم استخدام اختبار بيرسون لأيجاد نأثير مخاطر البنية التحتية على جودة التدقيق من وجهة نظر مدققي الحسابات للفرضية الفرعية الاولى (لا يوجد تأثثر ذو دلالة احصائية للبنية التحتية على جودة التنقيق من وجهة نظر مدققي الحسابات),(للفرضية الرئيسية الاولى)وكما مبين في الجدول رقم (ع ()) والذي يبين فيسـه أن القيمة الاحتمالية لجميع عناصر

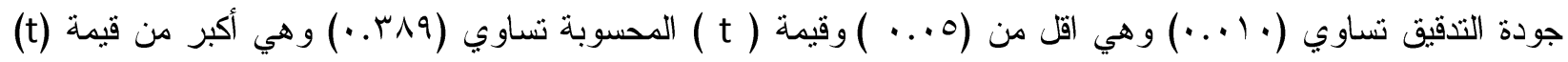

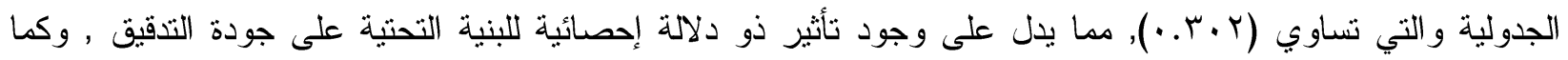

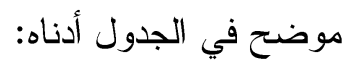

جدول رقم (ع 1) يبين معامل الارتباط بين البنية التحتية وجودة التدقيق

\begin{tabular}{|c|c|c|c|c|c|c|c|}
\hline جميع عناصر التدقيق & المدققلال & جودة اداء العمليات & جودة التقريز & جودة المدقق & جودة الخدمة & الإحصاءات & المحور \\
\hline$(\cdot . r \wedge q)$ & $(. . \vee V r)$ & $(\cdot . r \wedge . \quad)$ & ( ) & (. I ) & $(\cdot \leqslant \wedge \cdot)$ & معامل الارنباط & \multirow[t]{3}{*}{ البنية التحتية } \\
\hline$(\cdot \cdot 1 \cdot)$ & $($ (.rฯ^) & $\ldots 79$ & $(\ldots r \cdot)$ & $\left(. .1 \mu_{0}\right)$ & $(\cdots+)$ & القيمة الاحتمالية & \\
\hline$\varepsilon r$ & $\leqslant r$ & s & $\leqslant r$ & $\leqslant r$ & $\leqslant r$ & حجم العينة & \\
\hline
\end{tabular}

يثير الجدول رقم ( ع () الى أن جودة المدقق وجودة اداء العمليات واستقلال المدقق غير مؤثرة وغير معنوية . 
الفرضية الفرعية الثانية (لا يوجد ثأثير ذو دلالة احصائية لمخاطر عمليات الاتصال على جودة التدقيق من وجهة نظر مدققي الحسابات), وقد تم استخدام اختبار بيرسون لأيجاد ذلك التأثنر, وقد تبين أن القيمة الاحتمالية لجميع عناصر جودة التدقيق تساسوي

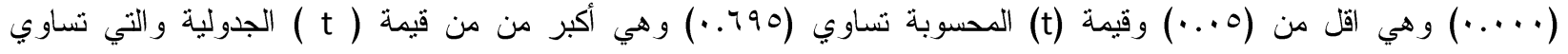
(ץ • r. •) مما يدل على وجود تأثير عند مستوى الدلالة الاحصائية (0...) لمخاطر عمليات الاتصال على جودة التذقيق وكما مبين

$$
\text { في الجدول رقم (10) (10) (10) }
$$

جدول رقم (10) يبين معامل الارتباط بين مخاطر عمليات الاتصال وجودة التنقيق

\begin{tabular}{|c|c|c|c|c|c|c|c|}
\hline جودة التدقيق عناصر & المدققلال & جودة اداء العمليات & جودة التقرير & جودة المدقق & جودة الخدمة & الاحصاءات & المحور \\
\hline$(. .790)$ & $(\cdot \pi r \cdot)$ & $(\cdot .509)$ & $(\cdot \vee \vee \vee 0)$ & $(.07 \varepsilon)$ & $(.7 .0)$ & معامل الارتباط & \multirow{3}{*}{ علاتصات } \\
\hline$(\cdots \cdots)$ & $(\cdot . r)$ & $\cdots r$ & $(\cdots \cdots)$ & $(\cdots \cdots)$ & $(\cdots \cdots)$ & القيمة الاحتمالية & \\
\hline$\varepsilon r$ & $\varepsilon r$ & $\varepsilon r$ & $\varepsilon r$ & \& & $\varepsilon r$ & حجم العينة & \\
\hline
\end{tabular}

الفرضية الفرعية الثالثة لا يوجد تأثير ذو دلالة احصائية لمخاطر عمليات التطبيقات على جودة التذقيق من وجهة نظر مدققي الحسابات), وقد تم استخدام اختبار بيرسون لأيجاد ذلك التأثثر, وقد تبين أن القيمة الاحتمالية لجميع عناصر جوسدة

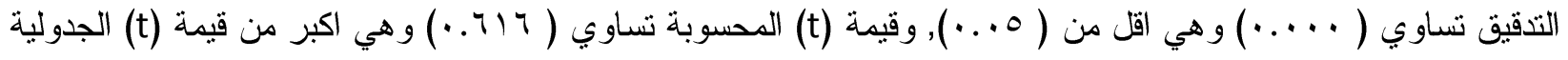
و التي تساوي (r •r.•) مما يدل على وجود تأثير عند مستوى الدلالة (0. . ) لمخاطر التطبيقات على جودة التدقيق وكما مبين في الجدول رقم (7 (1):

جدول رقم (7 (1) يبين معامل الارتباط بين مخاطر التطبيقات وجودة التذقيق

\begin{tabular}{|c|c|c|c|c|c|c|c|}
\hline جوديع عناصر التدقيق & استقلال & جودة اداء العمليات & جودة التقرير & جودة المدقق & جودة الخدمة & الاحصاءات & المحور \\
\hline$(. .790)$ & $(. r \leqslant 0)$ & $(. .219)$ & $(\cdot .7 \ldots)$ & $\left(. . \leqslant r_{0}\right)$ & $(. T / V)$ & معامل الارتباط & \multirow[t]{3}{*}{ التطبيقات } \\
\hline$(\cdots \cdots)$ & $(\ldots r r)$ & $\ldots 0$ & $(\cdots \cdots)$ & $(\cdots) \varepsilon$ & $(\cdots \cdots)$ & القيمة الاحتمالية & \\
\hline$\varepsilon r$ & $\varepsilon r$ & « & s & $\varepsilon$ & sr & حجم العينة & \\
\hline
\end{tabular}


أما الفرضية الرئيسية الثانية ( توجد فروقات ذو دلالة احصائية في متوسطات استجابات المبحوثين حول اثر مخاطر مهنة التدقيق الالكتروني على جودة التدقيق تعزى ( المؤهل العلمي , العمر بالسنوات وعدد سنوات الخبرة) فقد تم استخدام نحليل التباين الآحادي لختبار تلك الفروقات وكالآتي:

الفرضية الفرعية الاولى ( توجد فروقات ذات دلالة احصائية في متوسطات استجابات المبحوثين حول اثر مخاطر التدقيق الالكتروني تعزى الى المؤهل العلمي عند مستوى الدلالة (0. . ), وقد تبين أن قيمة (t) المحسوبة لجميع المحاور

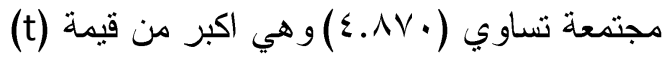

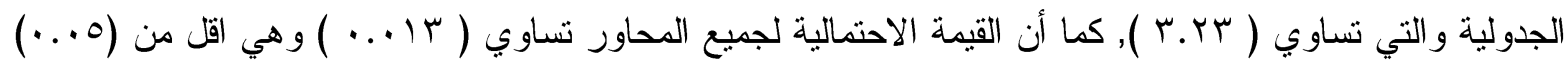
مما يدل على وجود فروق بين اجابات افراد العينة حول أثثر مخاطر مهنة التنقيق الالكتروني على جودة التدقيق تعزى إلى

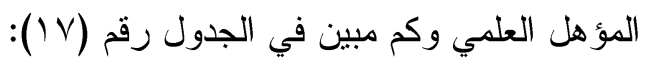

جدول رقم ( V ) يبين نتائج تحليل التباين الاحادي حول أثر مخاطر التدقيق الاكتروني على جودة التدقيق تعزى اللمؤهل العلمي

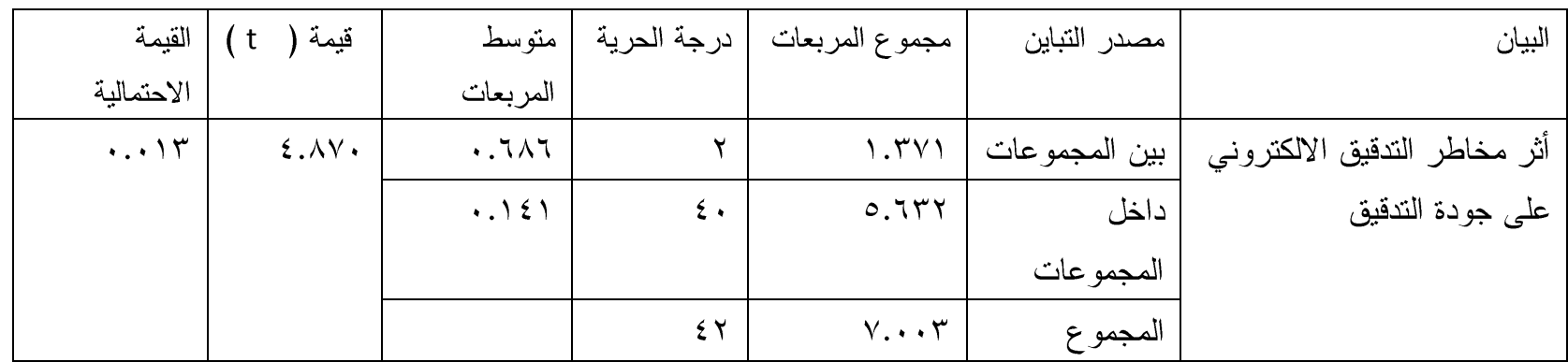

أما الفرضية الفرعية الثانية ( توجد فروقات ذات دلالة احصائية في متوسطات استجابات المبحوثين حول أثر مخاطر التنقيق الالكتروني تعزى إلى العمر بالسنوات عند مستوى دلالة ( (. . ) فقد تبين أن قيمة ( t) المحسوبة لجميع المحاور

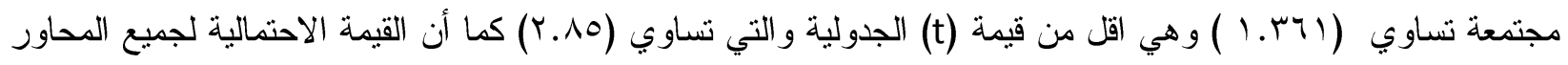

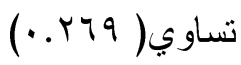
و هي أكبر من ( . . . ) مما يدل على وجود فروقات في اجابات افراد العينة تعزى للعمر وكما مبين في الجدول رقم 
Journal of University of Babylon for Pure and Applied Sciences,Vol.(26), No.(7): 2018

جدول رقم (1 ا) يبين نتائج تحليل التباين الاحادي حول اثر مخاطر التدقيق الاكتروني على جودة التدقيق تعزى للعمر

\begin{tabular}{|c|c|c|c|c|c|c|}
\hline الإحتمالية & قيمة ( t ) & منوسط & درجة الحرية & مجموع المربعات & مصدر التباين & البيان \\
\hline \multirow[t]{3}{*}{. .179} & \multirow[t]{3}{*}{1.471} &.$M Y_{I}$ & $r$ & $.77 \leqslant$ & بين المجمو عات & \multirow{3}{*}{ على جودة التدقيق التثقيق الاكتروني } \\
\hline & & (17) & $r q$ & T.น & داخل & \\
\hline & & & $\leqslant r$ & $v \ldots r$ & المجموع & \\
\hline
\end{tabular}

اما الفرضية الفرعية الثالثة (توجد فروقات ذات دلالة احصائية في متوسطات استجابات المبحوثين حول اثر مخاطر التدقيق الاككتروني تعزى الى عدد سنوات الخبرة عند مستوى دلالة (0. . •) فقد تبين أن قيمة (t) المحسوبة لجميع المحاور

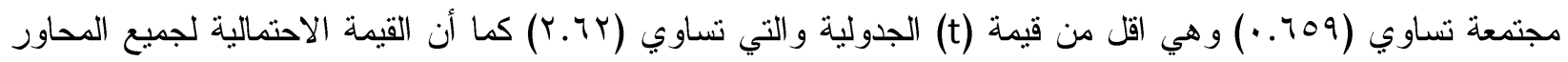
تساوي (گr

و هي اكبر من (0. . ) مما يدل على وجود فروقات في اجابات افراد العينة تعزى للعمر وكما مبين في الجدول رقم (9 (): جدول رقم ( 9 ) يبين نتائج تحليل التباين الاحادي حول اثر مخاطر التدقيق الاكتروني على جودة التدقيق تعزى لعدد سنوات الخبرة

\begin{tabular}{|c|c|c|c|c|c|c|}
\hline الاحتمالية & قيمة ( t ) & متوسط & درجة الحرية & مجموع المربعات & مصدر التباين & البيان \\
\hline \multirow[t]{3}{*}{$.7 r \leq$} & \multirow[t]{3}{*}{.709} & $.11 \leq$ & $\varepsilon$ & $.0 \leqslant 0 \leqslant$ & بين المجموعات & \multirow{3}{*}{ على جودة التثقيق الثر مخرق الاككتروني } \\
\hline & &.$I V Y$ & rᄉ & $7.0 \leq 9$ & المجمو عات & \\
\hline & & & $\varepsilon r$ & $v \ldots r$ & المجموع & \\
\hline
\end{tabular}

مما سبق تبين أثز كل من العو امل الخاصة بالمؤهل العلمي , العدر بالسنوات وعدد سنوات الخبرة في ابراز مخاطر التدقيق الاككتروني على جودة التدقيق وأتضح وجود علاقة ايجابية قوية , حيث أن زيادة كل من العو امل المذكورة يزيد من فعالية اكتشاف لمخاطر التدقيق الالكتروني. 
Journal of University of Babylon for Pure and Applied Sciences,Vol.(26), No.(7): 2018

$$
\begin{gathered}
\text { الاستتناجات و التوصيات } \\
\text { اولا : الاستتناجات: }
\end{gathered}
$$

ا- تؤثر دقة المعلومات الناتجة من النظام المحاسبي ووضوحها على مستوى مخاطر التدقيق بشكل عام سواء أكان يدوياً ام الكترونياً .

r- الاهتمام بفعالية اجراءات الأمن والحماية للبرامج والتطبيقات يسه في تخفيض مخاطر البنى التحتية و التطبيقات وعمليات الاتصال.

ب- بذل العناية المهنية الكافية من قبل المدقق و استخدام اسلوب المقارنات الزمانية و المكانية لبيانات العمبل بكفاءة وفعالية بسهم في تخفيض مخاطر التدقيق الاككتروني بشكل عام •

ع- تمتع المدققين بالمؤهلات والامكانيات اللازمة لممارسة التدقيق الاككتروني تساعد في سرعة اكتشاف الاخطاء وتقليل مخاطر التدقيق الالكتروني.

0- تطبيق البرامج ذات المواصفات والنوعية الجيدة في عمليات التدقيق الالكتروني من شأنه أن يؤدي إلى الاطمئنان على سلامة العمل وتقليل مخاطر التذقيق الاككتروني • 4- تقديم الخدمات للعملاء عند لجوئهم اليهم في عمليات التذقيق الالكتروني يؤدي إلى توفير جودة التنقيق • V- تمتع المدققين بالصفات الاخلاقية الجيدة عند اكتشاف الاخطاء يؤدي الى جودة عملية التدقيق . 1- شعور العملاء بالتقة و الأمان بمحتويات تقارير التدقيق يؤدي إلى جودة عملية التذقيق . 9- تمتع المدققين بدرجة عالية من الاستقلالية تؤدي إلى التقليل من مخاطر عملية التدقيق وتحقق جودة التدقيق . • 1- أظهرت نتائج التحليل الاحصائي عدم وجود فروق بين اجابات افراد العينة حول اثر مخاطر التدقيق الالكتروني على جودة التدقيق تعود الى العمر وعدد سنوات الخبرة بينما توجد فروق بين الأجابات ذات دلالة تعزى إلى المؤهل العلمي . 
ا- ضرورة وضوح المعلومات الناتجة من النظام المحاسبي لكون ذلك يؤثر على مستوى مخاطر التدقيق بشكل كبير سو اء أكان يدوياً ام الكترونياً .

r- ضرورة الاهتمام بفعالية اجر اءات لأامن والحماية للبر امج والتطبيقات لكون ذلك يسهم في تخفيض مخاطر البنى التحنية و التطبيقات و عمليات الاتصال .

س- ضرورة بذل العناية المهنية الكافية من قبل المدقق واستخدام اسلوب المقارنات الزمانية و المكانية لبيانات العميل بكفاءة وفعالية يسهم في تخفيض مخاطر التدقيق الاككتروني بشكل عام • ع- ضرورة تمتع المدققين بالمؤهلات والامكانيات اللازمة لممارسة التدقيق الالكتروني , لأن ذلك يساعد في سرعة اكتشاف الاخطاء وتقليل مخاطر التدقيق الاككتروني.

0- الاهتمام بتطبيق البرامج ذات المواصفات والنوعية الجيدة في عمليات التدقيق الالكتروني من شأنه أن يؤدي الى الاطمئان الى سلامة العمل وتقليل مخاطر التدقيق الالكتروني • צ- ينبغي الاهتمام بتقديم الخدمات للعملاء عند لجوءهم اليهم في عمليات التنقيق الالكتروني , لأن ذلك يؤدي الى توفير جودة التدقيق

V- يستلزم تمتع المدققين بالصفات الاخلاقية الجيدة عند اكتشاف الاخطاء , لأن ذلك يؤدي إلى جودة عملية التدقيق . 1- الحرص على شعور العملاء بالتقة والامان بمحتويات تقارير التنقيق , لأن ذلك يؤدي الى جودة عملية التدقيق . 9- ضرورة تمتع المدققين بدرجة عالية من الاستقلالية من شأنه أن يؤدي إلى التقليل من مخاطر عملية التنقيق وتحقق جودة التدقيق • 1- الزام المدققين بالالتحاق بالدورات التدريبية في مجال التدقيق , لأن ذلك يؤدي الى زيادة قدراتهم المهنية ويقلل من اخطار التدقيق الالكتروني . 
1- الصبّان, محمد سمير, علي , عبد الوهاب تصر , (11 • ب) المر اجعة الخارجية المفاهيم الاساسية واليات التطبيق, عمان الاردن, مطبعة زمزم للطباعة و النشر • r- عبد المجيد, محمد محمود, ( 9 . . r) المفاهيم العلمية والاساليب الفنية الحديثة في المر اجعة ,القاهرة, جمهورية مصر العربية, مطبعة النيل للطباعة و النشر

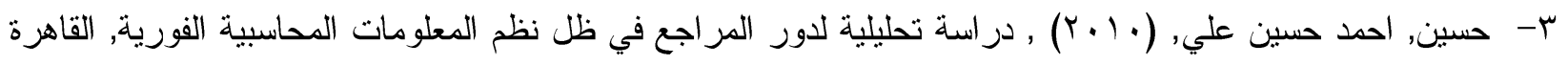
، جمهورية مصر العربية, مطبعة دار السلام للطباعة والنشر .

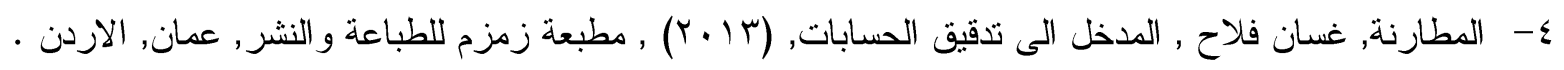
0- عثمان , عثمان حسين ,امين , يسري , (1) (1), قياس اثر مخاطر الاعمال على جودة عملية التذقيق , مجلة الفكر المحاسبي جمهورية مصر العربية , المجلد الخامس عشر , العدد الثاني. צ- إبر اهيم , احمد علي, (• (بr) الخطيط لعملية المراجعة , الاسكندرية , جمعورية مصر العربية , , مطبعة النيل للطباعة و النشر •

7- Arens, A,Loebeche J(.2005.) "Auditing- integrated Approach "prentice-Hall interaation,Inc,USA

^ـ الديب, عوض لبيب, شحاتة السيد, شحاتة, ( 9 . ؟ ) , اصول المراجعة الخارجية , الاسكندرية, دار التعليم الجامعي للطباعة و النشر و التوزيع •

9- عيسى, سمير كامل, ( ^ . . r) , اثز جودة المراجعة الخارجية على عمليات ادارة الارباح, مجلة كلية التجارة للبحوث العلمية العدد الثاني المجلد (0؛) , جمهورية مصر العربية ..

• 1- جمعة, أحمد حلمي, ( 9 . ب) , دراسات وبحوث قي التذقيق و التأثير , عمان , الاردن , مطبعة زمزم للطباعة و النشر

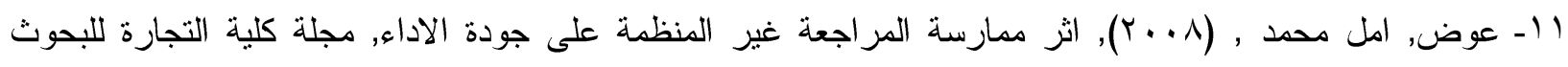
العلمية جمهورية مصر العربية, العدد الثاني, المجلد الخامس والاربعون.

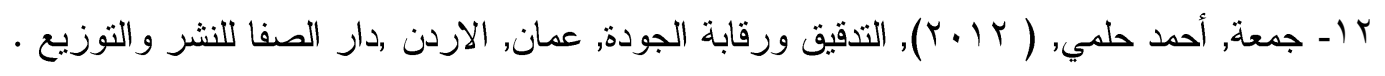

13- Knapp , A,Loebeche R . .2008 " Auditing- Approach " prentice-Hall interaation,Inc,USA . ع ا - ر راضي , محمد سامي , (11 + r) , موسوعة المر اجعة المتقدمة , الاسكندرية , دار التعليم الجامعي للطباعة والنشر. 
1 10 باعجاجة, سالم سعيد, (V. . (Y), جودة اداء مكاتب المحاسبة والمراجعة, المجلة العلمية لقطاع كليات التجارة جمهورية مصر العربية, العدد الاول, المجلد الاول.

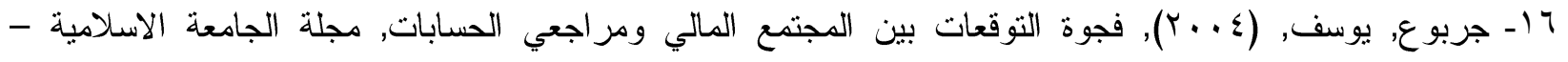
الدر اسات الانسانية فلسطين, المجلد الثاني عشر, العدد الثاني.

Vا - حمدان, علاء محمد, ( Y • Y ) ,العو امل المؤثرة في جودة الارباح , مجلة الجامعة الانسانية - الدراسات الإسلامية , فلسطين المجلد العشرون, العدد الاول .

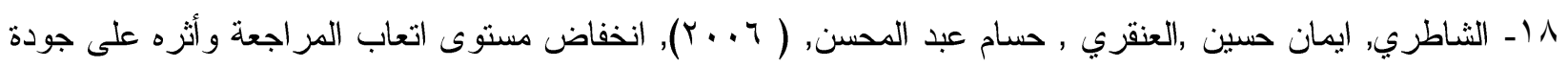
الاداء المهني مجلة جامعة الملك عبد العزيز , المجلد العشرون - العدد الاول. 